\title{
Attitudes of Paramedic Students towards Specific Medical Conditions: A Four-Year Study
}

\author{
Brett A. Williams \\ Monash University, brett.williams@monash.edu \\ Malcolm J. Boyle \\ Monash University \\ Stuart Howard \\ Monash University
}

Follow this and additional works at: https://nsuworks.nova.edu/ijahsp

Part of the Emergency Medicine Commons, and the Medical Education Commons

\section{Recommended Citation}

Williams BA, Boyle MJ, Howard S. Attitudes of Paramedic Students towards Specific Medical Conditions: A Four-Year Study. The Internet Journal of Allied Health Sciences and Practice. 2015 Apr 01;13(2), Article 6.

This Manuscript is brought to you for free and open access by the College of Health Care Sciences at NSUWorks. It has been accepted for inclusion in Internet Journal of Allied Health Sciences and Practice by an authorized editor of NSUWorks. For more information, please contact nsuworks@nova.edu. 


\title{
Attitudes of Paramedic Students towards Specific Medical Conditions: A Four- Year Study
}

\begin{abstract}
Purpose: The purpose of this study was to determine the attitude of first year students entering a paramedic course over 4 consecutive yearly intakes toward patients with intellectual disability, substance abuse, attempted suicide, and acute mental illness. Method: The students' attitude towards four medical conditions commonly encountered in the out-of-hospital setting was assessed using the Medical Condition Regard Scale (MCRS). The MCRS score ranges from 11 to 66. Results: 230 students in Victoria, Australia, participated in the study; $66 \%$ were female, and $76 \%$ of all students $<21$ years of age. Students showed the most negative attitudes towards substance abuse, mean 35(SD+6.6), and the most positive attitude toward intellectual disability, mean 38.2(SD+6.3). Students in 2008 cohort displayed significantly higher regard for all medical conditions (pConclusions: The study findings suggest that these students in Victoria, Australia, entering an undergraduate paramedic or paramedic/nursing course have a relatively poor attitude towards the four reviewed medical conditions, particularly substance abuse.
\end{abstract}




\title{
IVAHSP
}

\section{The Internet Journal of Allied Health Sciences and Practice}

Dedicated to allied health professional practice and education

Vol. 13 No. 2 ISSN 1540-580X

\section{Attitudes of Paramedic Students towards Specific Medical Conditions: A Four-Year Study}

\author{
Brett Williams, $\mathrm{PhD}{ }^{1}$ \\ Malcolm Boyle, PhD2 \\ Stuart Howard, BEH ${ }^{3}$
}

1. Department Head, Community Emergency Health and Paramedic Practice, Monash University, Melbourne, Victoria

2. Senior Lecturer, Community Emergency Health and Paramedic Practice, Monash University, Melbourne, Victoria

3. Research Assistant, Community Emergency Health and Paramedic Practice, Monash University, Melbourne, Victoria

Australia

\begin{abstract}
Purpose: The purpose of this study was to determine the attitude of first year students entering a paramedic course over 4 consecutive yearly intakes toward patients with intellectual disability, substance abuse, attempted suicide, and acute mental illness. Method: The students' attitude towards four medical conditions commonly encountered in the out-of-hospital setting was assessed using the Medical Condition Regard Scale (MCRS). The MCRS score ranges from 11 to 66 . Results: 230 students in Victoria, Australia, participated in the study; $66 \%$ were female, and $76 \%$ of all students $<21$ years of age. Students showed the most negative attitudes towards substance abuse, mean 35(SD+6.6), and the most positive attitude toward intellectual disability, mean 38.2(SD+6.3). Students in 2008 cohort displayed significantly higher regard for all medical conditions $(p<0.05)$. The 2009 and 2010 study participants demonstrated significantly lower regard, mean $36(p=0.01)$ and mean $36.2(p=0.018)$, for intellectual disability cases when compared to the most recent 2011 study group; mean 38.6. Conclusions: The study findings suggest that these students in Victoria, Australia, entering an undergraduate paramedic or paramedic/nursing course have a relatively poor attitude towards the four reviewed medical conditions, particularly substance abuse.
\end{abstract}

\section{INTRODUCTION}

Since its inception as a psychological term in 1897, empathetic behaviour and the attitudes of healthcare professionals towards patients have been widely regarded as a crucial factor in achieving positive health outcomes. ${ }^{1-3}$ Whilst there is no universal definition for empathy in regard to healthcare, Hojat el al propose that "empathy is a predominantly cognitive attribute (rather than emotional) that involves an understanding (rather than feeling) of experiences, concerns, and perspectives of the patient, combined with a capacity to communicate this understanding." 3 Unlike sympathy, displaying empathy carries with it no risk of becoming personally involved and thus does not jeopardise clinical neutrality, personal resilience, and decision-making abilities. ${ }^{2,3}$ For this reason, it is a desirable trait amongst all health professionals. ${ }^{4}$

The effects of increased empathy levels amongst health professionals is well documented and has been linked with increased patient compliance, superior communication, greater levels of patient satisfaction, and the formation of a more humanistic relationship between health professionals and patients. ${ }^{2,5-7}$ For the medical professional in particular, increased empathetic awareness also appears to facilitate greater diagnostic accuracy, improve competence in history taking abilities, and minimise the rate of clinical errors. $2,3,8$ 
Specific to the out-of-hospital setting, Regehr et al suggests that a cognitive empathetic approach allows paramedics to develop an internal frame of reference in which they can consider the consequences of actions upon the welfare of others whilst still acting in the best interest of patients. ${ }^{9}$ A noteworthy example of this found in the literature is in cases of SIDS patients, where displays of empathy from paramedics have been of the utmost importance during the grieving process for parents in both the immediate period and in the prevailing years to come. ${ }^{9}$

Empathy becomes particularly important when it comes to certain medical conditions that over the years have been associated with various stigmas, stereotypes, and negativity.10 Preconceived notions of patients and medical conditions are major impediments to the provision of equal healthcare and can contribute to inadequacy in the level of care delivered to a patient whilst also increasing the potential for a negative outcome. Amongst paramedics in particular, the regard shown to these patients in the out-of-hospital setting can establish trends that will continue through the entirety of a patient's journey. ${ }^{10}$

As empathetic behaviours amongst health students have been also shown to decline throughout the university, the early preconceived notions of students entering a paramedic degree can be indicative of future medical regard trends. $8,9,11,12$

The purpose of this study was to determine the attitude of students entering a paramedic course over 4 consecutive yearly intakes toward patients experiencing intellectual disability, substance abuse, attempts of suicide, and acute mental illness.

\section{METHODS \\ Study Design}

This was a cross sectional study utilising a paper-based questionnaire with convenience sampling of both first year paramedic students and first year paramedic/nursing double-degree students from a large Australian University.

\section{Populations and Setting}

The study was conducted within the Department of Community Emergency Health and Paramedic Practice at the Peninsula campus of Monash University, Victoria, Australia. All current first year paramedic and first year paramedic/nursing double-degree students were invited to participate in the study, with the only inclusion criteria being that students were enrolled full time in the first year of the aforementioned courses. Enrolment in the study occurred annually between 2008 and 2011 during semester one (March).

\section{Experimental Protocol}

The study used the Medical Conditions Regard Scale (MCRS), a 6-point Likert scale presenting participants with a number of statements concerning specific medical conditions that asks them to rate their agreement from $1=$ strongly disagree to $6=$ strongly agree. Each medical condition is scored on a scale from 11-66, with higher scores indicative of increasing regard for that specified medical condition. Designed to measure bias, emotions, expectations and regard, the MCRS has been found to be both a reliable and validated instrument. ${ }^{13}$ Based on current stigmas and the relative likelihood of paramedic exposure, the 4 conditions that were chosen to be investigated are cases of intellectual disability, substance abuse, attempted suicide, and acute mental illness.

\section{Analytical Methods and Outcomes}

The Statistical Package for Social Sciences (SPSS; Version 19.0) was used for data storage, tabulation, and the generation of descriptive statistics. Means were used to describe the descriptive data, and an independent samples t-test and analysis of variance (ANOVA) were used to determine if any differences existed between the universities, gender, year of study, and age groups. All tests were two tailed unless otherwise stated, and results were considered statistically significant if the $p$ value is < 0.05 .

\section{Ethics Approval}

Ethics approval was granted by the Monash University Human Research Ethics Committee. At the conclusion of a lecture, students were provided with the questionnaire and explanatory statement and were informed that participation in the study was voluntary. A department staff member not affiliated with the study facilitated the process and distribution of the questionnaires, which included both the MCRS and some brief demographic questions. Consent was implied by the voluntary completion and submission of each questionnaire. 


\section{RESULTS}

\section{Participant Demographics}

Between 2008 and 2011, 230 1st year students participated in the study. Of these, 150 students were enrolled in the single Bachelor of Emergency Health (paramedic) and the remaining 80 were enrolled in the Nursing/Emergency Health double degree. Almost two-thirds $(66 \%)$ of the participants were female and $34 \%$ male, which is consistent with enrolment statistics of the courses. Amongst the cohort, the majority of students were in their late teens and early 20 s. Seventy six percent $(76 \%)$ of all students were aged either 21 years or younger and $97 \%$ of students were either 30 years old or younger. This demographic distribution is expressed in Table 1.

\begin{tabular}{|c|c|c|}
\hline Variable & Descriptor & $n(\%)$ \\
\hline \multirow[t]{2}{*}{ Gender } & Male & 78 (33.9) \\
\hline & Female & $152(66.1)$ \\
\hline \multirow[t]{6}{*}{ Age } & $<21$ years & $175(76.1)$ \\
\hline & $22-25$ years & $34(14.8)$ \\
\hline & $26-30$ years & $14(6.1)$ \\
\hline & $31-35$ years & $4(1.7)$ \\
\hline & $36-45$ years & $2(0.9)$ \\
\hline & $>45$ years & $1(0.4)$ \\
\hline \multirow[t]{2}{*}{ Course Type } & Single Degree & $150(65.2)$ \\
\hline & Double Degree & $80(34.8)$ \\
\hline \multirow[t]{4}{*}{ Entry Years } & 2008 & $17(7.4)$ \\
\hline & 2009 & $99(43)$ \\
\hline & 2010 & $46(20)$ \\
\hline & 2011 & 68 (29.6) \\
\hline
\end{tabular}

\section{Mean Scores}

Table 2 (next page) depicts the mean MCRS scores across the 4-year study cohort for each individual condition. Mean MCRS score for intellectual disability cases was $38.2(S D \pm 6.3)$. The 2008 cohort had the highest MCRS at a score of $55.0(S D \pm 4.8)$, and the 2009 cohort had the lowest score of 36.1 (SD+3.9). For substance abuse cases, mean MCRS was $35(S D \pm 6.6)$, with the 2008 cohort displaying the highest mean score of $45.7(S D+8.8)$ and the 2010 cohort again displaying the lowest score of 32.6 $(S D+5.9)$. Mean MCRS for attempted suicide cases was $37.1(S D \pm 7.4)$, with 2008 and 2010 displaying the highest and lowest scores at $54.2\left(\mathrm{SD}_{\mathbf{1}}+5.1\right)$ and $34.8(\mathrm{SD}+7.1)$ respectively. Lastly, mean MCRS in acute mental illness patients was $38.1(\mathrm{SD}+6.8)$. 
Table 2. Mean MCRS Scores

\begin{tabular}{|l|l|l|l|l|l|}
\hline Variable & \multicolumn{1}{|c|}{ Descriptor } & \multicolumn{1}{|c|}{$\begin{array}{c}\text { Mean MCRS } \\
\text { Intellectual Disability } \\
\text { (SD) }\end{array}$} & $\begin{array}{c}\text { Mean MCRS } \\
\text { Substance } \\
\text { Abuse } \\
\text { (SD) }\end{array}$ & $\begin{array}{c}\text { Mean MCRS } \\
\text { Attempted } \\
\text { Suicide } \\
\text { (SD) }\end{array}$ & $\begin{array}{c}\text { Mean MCRS } \\
\text { Acute Mental } \\
\text { IIness } \\
\text { (SD) }\end{array}$ \\
\hline First Years & 2008 & $55.06(4.82)$ & $45.71(8.80)$ & $54.24(5.09)$ & $55.24(3.86)$ \\
\cline { 2 - 6 } & 2009 & $36.04(3.92)$ & $34.11(5.79)$ & $35.45(5.58)$ & $37.06(3.96)$ \\
\cline { 2 - 6 } & 2010 & $36.15(4.42)$ & $32.67(5.92)$ & $34.77(7.05)$ & $34.95(6.75)$ \\
\cline { 2 - 6 } & 2011 & $38.56(3.48)$ & $35.12(4.93)$ & $36.78(4.36)$ & $37.18(4.25)$ \\
\cline { 2 - 6 } & Total & $38.22(6.31)$ & $34.98(6.61)$ & $37.13(7.41)$ & $38.06(6.81)$ \\
\hline \multirow{4}{*}{ Course Type } & Single Degree & $38.95(7.05)$ & $35.36(7.07)$ & $37.88(7.95)$ & $38.97(7.43)$ \\
\cline { 2 - 6 } & Double Degree & $36.88(4.41)$ & $34.26(5.60)$ & $35.79(6.12)$ & $36.39(5.12)$ \\
\hline \multirow{3}{*}{ Gender } & Female & $38.69(6.70)$ & $34.86(7.13)$ & $37.11(7.58)$ & $37.91(7.12)$ \\
\cline { 2 - 6 } & Male & $37.38(5.35)$ & $35.21(5.48)$ & $37.17(7.11)$ & $38.35(6.18)$ \\
\hline & $<21$ years & $38.12(6.51)$ & $34.88(6.69)$ & $37.43(7.30)$ & $38.11(7.16)$ \\
\cline { 2 - 6 } & $22-25$ years & $37.03(3.77)$ & $34.06(6.60)$ & $35.53(6.29)$ & $37.00(3.58)$ \\
\cline { 2 - 6 } & $26-30$ years & $36.86(9.27)$ & $36.36(5.31)$ & $35.92(11.02)$ & $38.75(8.69)$ \\
\cline { 2 - 6 } & $31-35$ years & $40.25(10.59)$ & $36.75(6.94)$ & $38.25(8.99)$ & $39.00(6.58)$ \\
\cline { 2 - 6 } & $35-45$ & $45.00(12.72)$ & $44.00(4.24)$ & $43.50(2.12)$ & $45.00(8.485)$ \\
\cline { 2 - 6 } & $>45$ & $39.00(9.12)$ & $39.00(7.45)$ & $40.00(4.56)$ & $39.00(8.69)$ \\
\hline
\end{tabular}

The 2008 cohort had the highest score at $55.2(S D+3.9)$ and the 2010 students had the lowest score at $35(S D+6.8)$.

Table 3 displays comparative results and significance found within the study population. The 2008 cohort consistently displayed highest regard for all medical conditions; however, this may be a result of the low number of study participants compared to the remaining years. Also, the 2011 students displayed significantly higher medical regard for intellectual disabilities when compared to both the 2010 and 2009 intakes.

Table 3. Comparison of MCRS Scores

\begin{tabular}{|c|c|c|c|}
\hline Scale & Age & Gender & Course Type \\
\hline \multirow{2}{*}{ MCRS Intellectual Disability } & $\mathrm{F}=0.867$ & $\mathrm{~F}=0.599$ & $\mathrm{~F}=5.593$ \\
\cline { 2 - 4 } & $\mathrm{p}=0.664$ & $\mathrm{p}=0.440$ & $\mathrm{p}=0.019^{*}$ \\
\hline \multirow{2}{*}{ MCRS Substance Abuse } & $\mathrm{F}=1.140$ & $\mathrm{~F}=0.138$ & $\mathrm{~F}=1.440$ \\
\cline { 2 - 4 } & $\mathrm{p}=0.340$ & $\mathrm{p}=0.710$ & $\mathrm{p}=0.231$ \\
\hline \multirow{2}{*}{ MCRS Attempted Suicide } & $\mathrm{F}=0.781$ & $\mathrm{~F}=0.003$ & $\mathrm{~F}=4.150$ \\
\cline { 2 - 4 } & $\mathrm{p}=0.565$ & $\mathrm{p}=0.959$ & $\mathrm{p}=0.043^{*}$ \\
\hline MCRS Acute Mental IlIness & $\mathrm{F}=0.617$ & $\mathrm{~F}=0.215$ & $\mathrm{~F}=7.640$ \\
\cline { 2 - 4 } & $\mathrm{p}=0.687$ & $\mathrm{p}=0.643$ & $\mathrm{p}=0.006^{*}$ \\
\hline
\end{tabular}

${ }^{*}=p<0.05$

Whilst not necessarily significant, there was a trend existent across yearly intakes, with 2008 students scoring highest across all conditions, followed by the 2011 cohort, the 2009 cohort and lastly the 2010 students. This suggests that changes to the continually developing paramedic course model, even in its early stages, have impacted student responses to the questionnaire.

There were significant differences noted between course enrolments for the single degree and double-degree cohorts. For all but the substance abuse cases, single degree paramedic student displayed significantly higher MCRS scores when compared to their double-degree paramedic nursing peers

Unlike previous studies, there was no significant difference noted between genders and age groups across any yearly intake. 


\section{DISCUSSION}

These data come from some of the first known research in Australia investigating preconceived medical regard in students beginning a paramedic degree. Previous studies investigating empathy levels amongst students, however, are indicative of a trend of low empathy amongst student paramedics. In a 2010 survey of 459 undergraduate students across six health disciplines, Boyle et al found paramedic students to have the lowest empathy scores amongst the professions. ${ }^{5} \mathrm{~A}$ further 2012 study by Williams et al reinforced this with very similar results across seven Australian undergraduate paramedic programs. ${ }^{7}$ The results found during this study specifically suggest that those students beginning a degree in paramedicine display a relatively poor attitude to the four reviewed and frequently stigmatised medical conditions. This is particularly apparent when we compare these results to that of other health professionals.

In 2012, McKenna et al utilised the MCRS to assess attitude for similar medical conditions amongst undergraduate nursing students and found mean results typically in the low 50's; significantly higher than the majority of our student paramedic scores falling within the 30 's. ${ }^{14}$ Similarly, studies reinforce this, with typical MCRS scores for physicians, psychologists, and allied health professionals using conditions typically ranging between 40 and 55.6,13,15,16 The 2008 intake did show results consistent with other health professions; however, the low number of participants within this intake may have potentially skewed these trends.

Inconsistent with the aforementioned studies, however, our results suggest that those students beginning a paramedic/nursing double degree show significantly lower regard for medical conditions when compared to their single paramedic degree counterparts. There are several possible explanations for this. It may be that even at the beginning of their studies, nursing students are more likely to develop maladaptive negative attitudes for the specific medical conditions earlier as a result of increased patient interactions and possible negative exchanges over the paramedic students. ${ }^{17,18}$ Other factors such as student ages, previous education, culture, past healthcare experiences, and differing course structures may offer explanations for these results; however, these trends require further longitudinal investigation. ${ }^{10,19}$

Across all four yearly intakes, it was found that substance abuse ranked the most poorly in terms of MCRS scores. As paramedics frequently encounter patients in acute substance abuse episodes, this is a concerning statistic. ${ }^{20}$ Research tells us that those patients with a history of substance abuse problems have better health outcomes when health professionals are accepting and non-judgemental of their condition. ${ }^{21}$ Reduced regard amongst health professionals may be responsible for a reduction in patients' willingness to reach out and seek help for their disorder. ${ }^{21}$ As the students involved in this study are only just beginning their degrees, these results highlight the need to invest in targeted educational curricula that increase student attitudes and awareness towards these type of medical conditions. ${ }^{22}$ The evidence suggests that student empathy levels in the coming years will decrease as a result of patient exposure, increased workload, time pressures, competiveness, and increased cynicism.4,8,18 Appropriate framing and investment into empathy syllabi early in university programs may prove beneficial in increasing medical condition regard awareness amongst paramedic students, ultimately targeted towards benefiting stigmatised patient groups. ${ }^{7}$

Reduced medical regard in paramedics may not necessarily be a negative thing and it may be that such a quality is required to work in the high-stress, out-of-hospital environment. Grevin suggests that lower empathy trends amongst paramedics may in fact be an adaptive mechanism that allows paramedics to perform their duties more effectively and without personal involvement in an environment where the suffering of others is a frequent occurrence. ${ }^{23}$ The 1996 cross-sectional study utilising the Emotional Empathy Scale also found that both experienced paramedics and student paramedics displayed significantly low mean empathy scores, indicating that lower empathy trends may be the result of personality traits amongst paramedics and not learned coping mechanisms ${ }^{23}$ As the university students involved in this current study do not undergo interview selections prior to enrolment in the course, future research may highlight the importance of investigating personality traits prior to student selection and any correlation and/or prediction towards improved empathetic behaviours.

Interestingly, this study found no significant differences in responses between participant genders and age groups. In the current literature, there is strong evidence that females typically have higher empathy levels when compared to their male counterparts. $., 10,18$ Various hypotheses for this include differing neural circulatory patterns in the brain, predispositions to emotionally-charged decision making, societal developmental differences, and maternal influence. ${ }^{24,25}$ Similarly, trends of higher MCRS scores amongst health students $>27$ years old have been suggested to be the result of additional life experiences presenting influencing factors on decision making abilities. ${ }^{10}$ The reason as to why no differences were noted amongst first year paramedic students within this study requires further horizon-based investigation.

Like every study, there are numerous limitations that may have potentially altered the results found. The use of convenience sampling may not necessarily be a fair representation of all students currently enrolled in the degree. Similarly too, MCRS results

(C) The Internet Journal of Allied Health Sciences and Practice, 2015 
must be interpreted cautiously as this study utilised a self-reporting questionnaire and students reported views and perceptions may differ from their actual attitude to clinical situations. Data from this study was collected from a single university only and therefore may also not be representative of paramedic students as a whole. Lastly, as only first year students were used for this study, trends upon regard levels throughout the course cannot be determined. A larger study involving all year levels across multiple universities would be of benefit for future research. It is important to also highlight that no major changes to either curricula were made throughout the study; therefore, MCRS results are likely to be based on factors other than those directly related to the curricula. Qualitative analysis and content review may have addressed this.

Because of the benefits heightened empathy awareness in stigmatised medical conditions can have towards patient outcomes, it is recommended that targeted educational curricula supporting this be utilised and promoted further within paramedic degree programs. Earlier exposure to patients may also be beneficial, with any stigmatising trends amongst students addressed early by professional staff. Doing so will not only benefit patients, but will also maintain and potentially enhance the quality and professionalism of future graduate paramedics within ambulance services. If such empathetic trends are a result of personality predispositions as this research may suggest, then it is recommended that concurrent studies also take place to investigate how heightened medical condition awareness impacts both paramedic career longevity and work satisfaction.

\section{CONCLUSION}

The results of this study suggest that students in Victoria, Australia, entering a paramedic degree show relatively poor attitudes to four notable and typically stigmatised medical conditions. Whilst it is unclear whether this is a beneficial trait within the unique and often stressful out-of-hospital environment, an abundance of research suggests that increased empathy levels in healthcare professionals ultimately improves both patient outcomes and the quality of care delivered to patients. The data from this study should be used by teaching staff to reconsider current educational models and address the need to introduce empathy syllabi early in paramedic education and training to offset any misconceptions regarding particular patient groups.

\section{REFERENCES}

1. Hemmerdinger JM, Stoddart SD, Lifford RJ. A systematic review of tests of empathy in medicine. BMC Medical Education. 2007;7:24. [PMID 17651477]

2. Hojat M. Empathy in patient care : antecedents, development, measurement, and outcomes. New York: Springer; 2007.

3. Hojat M, Louis DZ, Markham FW, Wender R, Rabinowitz C, Gonnella JS. Physicians' empathy and clinical outcomes for diabetic patients. Academic Medicine. 2011;86(3):359-64. [PMID 21248604]

4. Hojat M, Spandorfer J, Louis DZ, Gonnella JS. Empathic and Sympathetic Orientations Toward Patient Care: Conceptualization, Measurement, and Psychometrics. Academic Medicine. 2011;86(8):989-95. [PMID 21694570]

5. Boyle M, Williams B, Brown T, et al. Levels of empathy in undergraduate health science students. The Internet Journal of Medical Education. 2010;1(1).

6. Brown T, Williams B, Boyle M, Molloy A, McKenna L, Molloy L, Lewis B. Levels of empathy in undergraduate occupational therapy students. Occupational Therapy International. 2010;17(3):135-41. [PMID 20623554]

7. Williams B, Boyle M, Brightwell R, et al. Paramedic Empathy Levels: Results from Seven Australian Universities. International Journal of Emergency Services. 2012;1(2):111-21.

8. Williams BB, M. Brightwell S. Devenish S. Hartley P, McCall M. McMullen P, Munro G, O'Meara P, Webb V. An assessment of undergraduate paramedic students'empathy levels. International Journal of Medical Education. 2012;3:98-102.

9. Regehr C, Goldberg G, Hughes J. Exposure to human tragedy, empathy, and trauma in ambulance paramedics. American Journal of Orthopsychiatry. 2002;72(4):505-13. [PMID 15792036]

10. Nunes P, Williams S. Sa B, Stevenson K. A study of empathy decline in students from five health disciplines during their first year of training. International Journal of Medical Education. 2011;2:12-7.

11. Christison GW, Haviland MG, Riggs ML. The medical condition regard scale: measuring reactions to diagnoses. Academic Medicine. 2002;77(3):257-62. [PMID 11891166]

12. Nordby $\mathrm{H}, \mathrm{N} ø$ hr $\varnothing$. Communication and empathy in an emergency setting involving persons in crisis. Scandinavian Journal of Trauma, Resuscitation and Emergency Medicine. 2008;16(1):5. [PMID 18957067]

13. Christison GW, Haviland MG, Riggs ML. The medical condition regard scale: measuring reactions to diagnoses. Academic Medicine. 2002;77(3):257-62. [PMID 11891166]

14. McKenna L, Boyle M, Brown T, Williams B, Molloy A, Lewis B, Molloy L. Levels of empathy in undergraduate nursing students. International Journal of Nursing practice. 2012;18(3):246-51. [PMID 22621294]

15. Gilchrist G, Moskalewicz J, Slezakova S, Okruhlica L, Torrens M, Vajd R, Baldacchino A. Staff regard towards working with substance users: a European multicentre study. Addiction. 2011;106(6):1114-25. [PMID 21320230]

(c) The Internet Journal of Allied Health Sciences and Practice, 2015 
16. McKenna L, Boyle M, Brown T, Williams B, Molloy A, Lewis B, Molloy L. Levels of empathy in undergraduate midwifery students: An Australian cross-sectional study. Women and Birth. 2011;24(2):80-4. [PMID 21419742]

17. Rosenfield PJ, Jones L. Striking a balance: training medical students to provide empathetic care. Medical Education. 2004;38(9):927-33. [PMID 15327673]

18. Michalec B. An assessment of medical school stressors on preclinical students' levels of clinical empathy. Current Psychology. 2010;29(3):210-21.

19. Kelleher S, Cotter P. A descriptive study on emergency department doctors' and nurses' knowledge and attitudes concerning substance use and substance users. International Emergency Nursing. 2009;17(1):3-14. [PMID 19135010]

20. Lloyd BK, McElwee PR. Trends over time in characteristics of pharmaceutical drug - related ambulance attendances in Melbourne. Drug and Alcohol Review. 2011;30(3):271-80. [PMID 21545557]

21. Godlaski TM, Butler L, Heron M, Debord S, Cauvin L. A Qualitative Exploration of Engagement Among Rural Women Entering Substance User Treatment 1. Subst Use Misuse. 2009;44(1):62-83. [PMID 19137483]

22. Williams B, Boyle M, Brightwell R, et al. An assessment of undergraduate paramedic students' empathy levels. Int J Med Educ. 2011;3:98-102.

23. Grevin F. Posttraumatic stress disorder, ego defense mechanisms, and empathy among urban paramedics. Psychological Reports. 1996;79(2):483-95. [PMID 8909073]

24. Baron-Cohen S. The essential difference: male and female brains and the truth about autism. New York: Basic Books; 2004.

25. Derntl B, Finkelmeyer A, Eickhoff $\mathrm{S}$, et al. Multidimensional assessment of empathic abilities: neural correlates and gender differences. Psychoneuroendocrinology. 2010;35(1):67-82. [PMID 19914001]

\section{ACKNOWLEDGEMENTS}

We would like to thank the students for taking the time to complete the questionnaire 